\title{
Conference Wrap-up
}

\author{
Anthony C. Masi \\ Deputy Provost and Chief Information Officer \\ McGill University, CANADA \\ anthony.masi@mcgill.ca
}

Technology is disruptive. Information technology in higher education is very disruptive. The broad-based, grassroots, in-depth discussions that have taken place here today will help us as we think through the key issues and the already significant impact information technology has had and continues to have on our higher educational institutions. The principal theme that emerged today is just how important pedagogy is to our efforts at incorporating information and communications technology into our classrooms (and beyond). In particular, we all seemed very much concerned about identifying and implementing pedagogically sound approaches to the construction of Web-based learning or other distributed technology environments.

Flowing from the presentations and the discussions are a series of questions about what constitutes an ideal learning situation. Maybe I heard only what I wanted to hear, but I believe that our speakers and the conversations that followed their presentations pointed to at least four points that need to be followed up concerning a pedagogically sound approach to the introduction and proper use of information technology for higher education. Pedagogical sound practice for IT in the classroom:

1. must be customized to meet specific needs;

2. has to provide immediate and constructive feedback to the learners;

3. needs to motivate learners to go beyond any externally imposed requirements;

4. should help learners to build enduring conceptual structures.

If I had to identify the one surprising issue that we did not address as much today as we might or should have is the other side of the teaching coin, that is, learning - the environments in which students actually learn. In order to develop an ideal pedagogical framework for information technology, we have to develop more innovative designs in the way in which we integrate technology into the curriculum of our bricks and mortar environment. We also have to emphasize learning strategies, and not just teaching methods and instructional software, and we have to pay some attention, as several people mentioned today, especially in the roundtable discussions, to the issue of technological equity: how do we make sure that we distribute these things in an appropriate way across different segments of the university.

There are some difficulties with current pedagogical practices utilizing information technology. First, most of these practices are derived from studies of paper-based materials, if they are based on research at all. Second, they are inconsistently organized. Third, extant pedagogical practices for IT in teaching and learning environments generally do not address cross-cultural, linguistic or international diversity in the approaches that might be taken. Most of us here today are interested in the implementation of these technologies for improving the educational experiences of our undergraduate students. Universities periodically review major subject requirements to ensure that disciplinary education is well-suited to the preparation and educational goals of our students. I maintain that we should do the same for information technology as applied to that curriculum. All of us at this conference should leave here committed to demonstrating leadership and vision in implementing pedagogically sound approaches to IT in higher education, and ensuring that our campus infrastructures and production capabilities are sufficient to the task. 
Another observation about today's discussions of IT (if not presentations): they typically tended to focus on features that are NOT AT ALL particular to education. We want to take advantage of information technology to organize and communicate information efficiently and to collaborate better on common projects. Obviously, these are problems that are typical of the modern workplace, and not only to higher education. Further, each institution of higher learning has a particular educational identity and mission and it is not always possible to cross those internal boundaries in higher education, let alone those that divide us from industry.

We can use educational technology to support any educational philosophy, and that in part reflects the necessity of having an educational philosophy, and a pedagogical vision to guide the way we use information and communications technology in our classrooms or in providing education at a distance. One of the things that McGill is interested in is to try to create an undergraduate environment in which we have "apprentice scholars" whose undergraduate experience could be categorized as "research informed learning and teaching". McGill is a research-intensive university; that's not the mission of every university in the province, or in the country. At a researchintensive university, a major objective is to bring research into the classroom. There are ways in which information technology can, indeed, help us to do that. One of the things that today's presentations and discussions forced me to think about was the need to create collaborative environments that resonate with and are consonant with various educational philosophies. Again, the notion of bringing students in so that they can work collaboratively with faculty members by using information technologies is part of what we're trying to accomplish.
We were guided today to think about pedagogy in terms of active learning and project-based learning. The use of modern educational technology has to provide sufficient support for professors and their design teams (itself an emerging concept and challenge to academic administrators). Two themes that came up over and over again, either at the roundtables or at the workshops: it is important to remember that we need sufficient support for professors because professors cannot do IT alone; design teams are a requirement not a luxury.

In addition to a bit of a lack of emphasis on the learning side, another thing struck me today, and it may be because libraries in the McGill context report to me, but we need to think about the integration of libraries and librarians, both for information literacy and metadata issues in the design of learning objects themselves or of institutional repositories or of federated repositories to share this information. Librarians have a lot to offer and they should be brought in as part of the team. Another thing we have to remember is that we want to have a sound, targeted, specific set of pedagogical services, and sometimes that means being discipline-based and having local support.

There are two other things I think I learned today. One is we have to try to remove obstacles. In certain fundamental respects, faculty and students are not really sharing the same educational space. Students do not have the disciplinary skills, experience or learning that faculty have. After all, they are students. They also have a limited amount of time and energy to devote to any particular enterprise: there is a lot to do and to learn and little time to do it. We also need to have a rationale for what we at McGill are calling researchinformed learning. It is a route to a flexible education, and it is not graduate training or the increase of knowledge and scholarship, which is the goal of pure research. We want that research to enter the classroom and we want to have educational technology help us to make that delivery.

The second thing we have to do is to embrace opportunities. Teaching and learning using information technology have opened up a range of disciplinary techniques and tools that can bridge differences among various disciplines. The idea of "multidisciplinarity" also came across in several of the presentations today. It is not unusual to hear that sometimes these technologies are actually transforming scholarship. They are transforming the way research is conducted, and they can have an impact on the way we do our delivery on campus, as well as at a distance. This raises new problems for us and requires new strategies from us. Students are almost as experienced as scholars in terms of the knowledge they bring about information technology. We heard about the difficulties of re-educating or retraining older professors. I think that the first choice that Tony Bates ${ }^{2}$ gave today was that they could choose not to participate, choose not to employ them and leave that to someone else. We find ourselves with students working closely, and again, I think the emphasis on the learning needs to be a part of our discourse about using TIC in our pedagogy. Students may be teaching the teachers, but let us not forget that it is the faculty members, not just as subject matter experts, but it is faculty members who develop critical methodological and disciplinary information that is needed to develop principled, discipline-specific technology-aided instruction.

We also have to be willing to innovate and experiment, but to do so is costly. Not everything we do will in fact yield appropriate results, but we have to ask ourselves all the time what can this technology do for this specific educational goal we have raised? Which technological tools and ad- 
vancements will most benefit our students and professors? How can we seamlessly integrate technology into our classroombased experiences? How can we enhance collaboration and interactivity across disciplines and across spaces? What assessment measures and outcomes should we use? That is something we really have to think carefully about as we move forward, in particular given the costs that Bates pointed out in this afternoon's lecture.

There are future visions. I recently attended an Educause conference and one of the things that was discussed is just how much change is actually taking place from high performance learning spaces like the Wallenberg Center at Stanford University to the use of e-Portfolios, distributed collaboration, something called a "digital video collaboratory" which is a multimedia library on the Internet. We also heard about teachable agents, as powerful a way to learn as they are to teach, as well as the fact that some things that look like toys to us can actually have a major impact on the way in which we view the future developments of these technologies. And there are social responsibilities that go along with them.

There are at least three models that are presently available for us. One we are already using today - the desktop and portal technology, again as Bates illustrated with examples from the University of British Columbia. He then pointed out that there is a ubiquitous computing model that he thinks, again according to his video, might actually be available at the University of British Columbia next year. I think that is an exaggeration, it is the publicity that is going to be available. But the other thing that is emerging is multi-user virtual environment interfaces, and those are coming soon. We have at McGill experiments with "shared reality spaces" that can and will fundamentally change the way that we think about the future. I think it is very important that we did have this morning, in Gilbert Paquette's presentation, a future vision. We needed to have that. We need to think about IT in those terms, and we have to think about what impact IT has on our teaching and learning.

We also, however, have to face some realities. There are silos out there. Institutional repositories will remain isolated and available only on a local basis unless we develop international interdisciplinary repositories. But we are facing an uphill battle with academic publishers. We should not forget that there is a crisis in scholarly publication and incredible pressure on university libraries to purchase "access" to electronic materials. There is an enemy to openness out there in the form of the way in which publishers are treating academic materials. New designs for course management and learning management systems, as we heard again and we continue to hear critiques about the current designs, need to be developed and thought about. We need to think about "communities of practice", and we need to think about new tools like blogs and klogs that are being used all over the Internet.

We have to have practical and usable standards and tools that reflect our practices. We need good knowledge management tools and approaches to knowledge object creation and the repurposing and the use of those in disciplines that otherwise might not have understood that they could use them. In other words, how do we liberate the knowledge out of those objects and make them available for exchange? We also have to have dynamic sharing tools and protocols to support communities of practice and we have to have some sense that the costs are so great that we must engage in activities that will lower those costs for all of us.
The roundtables this morning emphasized several common themes, and I tried just to pick out the ones that were common:

- support services and support personnel in both implementation and operations;

- restructuring, reorganization, and interinstitutional relations;

- ways in which our institutions themselves are responsive to this kind of change and reorganization.

Expectations are changing and we have to be willing to rethink the questions that today's conference has raised, not just the answers we have attempted to provide. We need to undertake cost-benefit analyses, fully cognizant of the fact that there is a diversity of needs inside and across campuses, and that we have to always search for ways to make the models that we do develop fully scalable.

Methodology, chronology, follow-up and feedback were all emphasized in the roundtable discussions, as were the notions of scarce resources, unequal integration, inequalities in the ways in which the technologies are distributed and the necessity for multidisciplinarity. When we came back in the afternoon sessions to hear again about the quality of the courses and teaching that uses this technology and the role of the professors.

Several other important issues and I just want to focus on one: issues related to intellectual property rights are not going to go away. Indeed, intellectual property rights issues are emerging ever more frequently and with increasing intensity because of the investments that universities must make in designing these courses. If course development is no longer an individual professor's realm but rather entails an entire team, then we can no longer think about intellectual property rights for a course as belonging exclu- 
sively to one professor. This is likely to become a major concern and potentially contested terrain for higher education.

In the elaboration of the two scenarios from the presentations today, several interesting themes were raised. I would like to briefly discuss two of them. First, we need to consider organizational issues. It is absolutely fundamental. In order to have a successful implementation of a cross-university technology implementation we have to think carefully about all of the following things (among others): collaboration, formal and informal mechanisms for training, management of projects, what the team should look like, how the design, planning and engineering of the pedagogy will work, and what mechanisms we should put in place for quality control.

The second scenario, dealing with physical chemistry, was also very interesting if you focus on the fact that it was an attempt at helping us understand how to assess whether or not our teaching efforts have made a difference. How do we calculate the degree of perfection of our own use of things like log files to analyze the profiles of the users and how they are working?

I would also like to mention four other themes that were NOT discussed today. The first is the conceptualization of learning objects. Again I want to emphasize, do not forget librarians for metadata and information literacy. The second is conceptualizing and developing tools and platforms for pedagogical design. Although tips and tricks are extremely useful, they are not a substitute for pedagogical frameworks that support the implementation of information technology in our classrooms or in their delivery at a distance. Third, institutional support is not only centralized or decentralized. There is a third model - federated. Disciplinary-based expertise needs support in loco, but it must be coordinated to ensure scalability by having a federated model of cooperation, rather than being either totally centralized or decentralized. Finally, we must never lose sight of our objectives and concern with measuring the outcomes.

Let me just give you one anecdote. We have a chemistry course at McGill that for six years has been taught the same way except three years ago they introduced a mechanism for having the PowerPoints and the audio segments of every lecture available online. Initially people were worried that this would have an impact on class attendance. It did not. The professors have monitored attendance and the online availability of slides and audio did not have a negative impact. The second thing they noticed was that students actually expressed a higher level of satisfaction with the course when it had the new technology than when it was not available. But, the disconcerting third finding was that the technology made no measurable difference to the learning outcomes of the students as measured through their grades. Students did not appear to have learned anything more even though they were more satisfied and had additional access via the Web to the lecture materials. We need to think about those outcomes.

Let me try to draw out some conclusions from today's sessions are. First, we have to be advocates inside of our own institutions in order to make sure that they devote sufficient resources and devote more time and effort in order to stay ahead of the IT curve. Second, there are competitors out there who are waiting to take over distance education and even distributed learning environments from universities. We heard at lunch that Volkswagen is going to launch Auto University, and it is going to be both bricks and mortar and online. And they are opening their doors in Germany next year.
There are consortia of online institutions at the Master's level already, and of course the University of Phoenix in the United States is a good example of that model. Third, we have to make sure that our institutions consider information technology as strategic. Right now IT is often just considered as a cost of doing business. We have not been successful in making IT an explicit part of the mandates or the strategic plans of our institutions. Fourth, we have to emphasize learning as much as we do teaching, production, and delivery. This means broadening the pedagogical underpinnings to include librarians as partners to pedagogues, educational technologists, IT specialists, and professors as subject matter experts. Fifth, we must be willing to benchmark ourselves and be held to performance indicators based on best practices. And finally, to repeat an earlier message in this wrap-up, we have to overcome those obstacles and embrace opportunities.

\section{Notes}

${ }^{1}$ This text is a reconstruction of the closing remarks and PowerPoint presentation delivered at the end of the conference Instructional Engineering and ICTs: Practice and Research, organized by the CREPUQ (Conférence des recteurs et des principaux des universités du Québec) on November 26, 2004 at McGill University, Montréal (http://www.profetic.org/colloque2004).

2 Tony Bates was the Keynote Speaker at the Conference. He was the Director of Distance Education and Technology in the Continuing Studies Division of the University of British Columbia, Vancouver, Canada from 1995 to 2003 and also Research Team Leader of MAPLE, the Centre for Research into Managing and Planning Learning Environments in Education at the University of British Columbia. A video of his presentation at the Conference is available on the Conference Web site (http://www.profetic.org/colloque2004). 